\title{
Bitcoin Fiyatları ile Borsa İstanbul Endeksi Arasındaki Eşbütünleşme ve Nedensellik Iilişkisi
}

\begin{abstract}
Bitcoin Fiyatları ile Borsa İstanbul Endeksi Arasındaki Eşbütünleşme ve Nedensellik ỉişkisi

Öz

Kripto para olarak da adlandırılan dijital para fiyatlarındaki değişimler son yıllarda yatırımcıların oldukça ilgisini çekmiştir. Hızlı fiyat değişimlerinden getiri elde etmek isteyen yatırımcılar yeni bir varlık olan dijital paralara yönelmişlerdir. Bu doğrultuda, dijital paraların geleneksel menkul kıymetlerine alternatif olma ihtimalleri tartışılmaya başlanmıştır. Çalışmada, Bitcoin fiyatları ile Borsa İstanbul arasındaki eşbütünleşme ve nedensellik ilişkisini tespit etmek amaçlanmıştır. Bu kapsamda, Engle-Granger ve Gregory-Hansen eşbütünleşme testleri ile Toda-Yamamoto ve Hacker-Hatemi-J nedensellik testlerinden faydalanılmıştır. Bulgular, her iki eşbütünleşme testine göre Bitcoin fiyatları ile Borsa İstanbul endeks değeri arasında orta ve uzun vadede bir eşbütünleşme ilişkisinin olmadığını; nedensellik testlerinden sadece Toda-Yamamoto nedensellik testine göre Borsa İstanbul'dan Bitcoin fiyatlarına doğru tek yönlü nedensellik ilişkisi olduğunu göstermiştir.
\end{abstract}

Anahtar Kelimeler: Bitcoin, Dijital (Kripto) Para, Borsa İstanbul
The Cointegration and Causality Relationship between Bitcoin Prices and Borsa Istanbul Index

Abstract

Changes in digital money prices, also called crypto money, have attracted investors' interest in recent years. Investors who want to gain returns from rapid price changes have turned to digital currencies, which is a new asset. In this direction, the possibility of being an alternative to the traditional securities of digital money has begun to be discussed. In the study, it was aimed to determine the cointegration and causality relation between Bitcoin prices and Borsa Istanbul. In this context, Engle-Granger and GregoryHansen cointegration tests and Toda-Yamamoto and Hacker-Hatemi-J causality tests were used. Findings show that there is no cointegration relationship between the Bitcoin prices and Borsa İstanbul index value in the medium and long run according to both cointegration tests; just TodaYamamoto causality test shows that there is a one-way causality relationship from Borsa İstanbul to the Bitcoin prices.

Keywords: Bitcoin, Digital (Crypto) Currencies, Borsa İstanbul

\section{Giriş}

İnsanlık tarihi boyunca alışverişte farklı yöntemler kullanılmıştır. Trampa ya da diğer adıyla takas ile başlayan alışveriş işlemleri, ihtiyaçların değişmesi ve teknolojinin sunduğu imkânlarla çok farklı boyutlarda yapılmaya başlanmıştır. Alışveriş işlemlerinde para, kredi kartı, online ödeme, sanal kartlar, mobil ödeme gibi çeşitli yöntemler ile devam eden bu süreç günümüzde dijital para birimlerine kadar ulaşmıştır. Dijital paralar, genellikle geliştiricileri tarafından ihraç edilmektedir ve yine bu geliştiricilerce kontrol edilmektedir. Dijital paralar, herhangi bir kanuna tabi olmayıp belli bir sanal ortamın üyeleri tarafından kullanılmaktadır.

2008 yılında Satoshi Nakamoto takma isimli kişi ya da kişiler tarafından yayınlanan bir makale ile ortaya çıkan Bitcoin, bilinen ilk dijital paradır. Bitcoin, herhangi bir finansal aracı olma-

\footnotetext{
${ }^{1}$ Dr. Öğr. Üyesi, Hasan Kalyoncu Üniversitesi, iisBF, İşletme Bölümü, yunus.kilic@hku.edu.tr, Yazar ORCID bilgisi: https://orcid.org/0000-0002-9758-5118.

2 Dr. Öğr. Üyesi, Hasan Kalyoncu Üniversitesi, iisBF, ìktisat Bölümü, ibrahim.cutcu@hku.edu.tr, Yazar ORCID bilgisi: https://orcid.org/0000-0002-8655-1553.
} 
dan bir kişiden başka bir kişiye online ödeme imkânı sağlayan elektronik para olarak tanımlanmaktadır. Dijital paralar elektronik para ya da kripto para olarak da adlandırılabilmektedir. Bitcoin'in ortaya çıkışından sonra çok hızıı bir şekilde çok fazla sayıda kripto para üretilmeye başlanmıştır. Teknochain verilerine göre günümüzde 825 adet kripto para mevcuttur. Coinmarket verilerine göre ise dünyada 1.818 adet kripto para vardır. Gerek piyasa değeri gerekse işlem hacmi açısından dijital paralar içerisinde en popüleri Bitcoin'dir.

Ödeme, tasarruf ve yatırım aracı olarak kullanılan Bitcoin ile ilgili ilk işlem 2009 yılı Ocak ayında yapılmıştır. Bitcoin, reel ekonomi ile 22 Mayıs 2010 tarihinde tanışmıştır. Laszlo Hanyecz 10.000 Bitcoin (BTC) karşılığında iki adet pizza satın alarak, Bitcoin ile yapıldığı bilinen ilk alışverişi gerçekleştirmiştir. 22 Mayıs 2010 tarihi itibariyle 10.000 BTC karşılığı 25 Amerikan Dolarıdır (Koçoğlu vd., 2016: 79). 6 Ağustos 2018 tarihi itibari ile bu rakam yaklaşık 70 milyon dolardır.

Bitcoin sahibi olmak isteyen bir kişi üç şekilde Bitcoin elde edebilir (Rogojanu ve Badea, 2016: 107-108):

- Kişisel bilgisayarlar üzerinden "madencilik" (mining) adı verilen işlemle Bitcoin sahibi olunabilir. Bu süreçte, bilgisayarlar tarafından çeşitli problemler çözülerek Bitcoin üretimi yapılır. Söz konusu bilgisayarların yüksek performanslı olması gereklidir ve bu bilgisayarlar çok fazla enerji tüketmektedirler.

- Bitcoin ile gerçek paraları takas ederek Bitcoin sahibi olunabilir.

- Bitcoin ile ürün takası yapılarak Bitcoin sahibi olunabilir.

Bitcoin edinimi başlarda tamamen madencilik işlemleri ile yürümüştür. Ancak, reel ekonomide kullanılmaya başlandıkça para ve ürün takası şeklinde de hızla kabul görmüştür. Birçok ülkede birçok sektörde Bitcoin karşılığında mal ya da hizmet satın alınabilmektedir.

Bitcoin ortaya çıktıktan sonra fiyatı uzun süre çok fazla değişim göstermemiştir. Ancak 2017 yılı Mayıs ayından sonra piyasa değerinde olağandışı artışlar görülmeye başlanmıştır. 1 Mayıs 2017 tarihi itibariyle bir Bitcoin'in piyasa değeri 1.348\$ iken 16 Aralık 2017 tarihinde 19.497\$ ile tarihindeki en yüksek değere ulaşmıştır. 2018 yılı Ağustos ayının başlangıcında ise bir Bitcoin $7.000 \$$ seviyelerinde piyasa değerine sahiptir. 2017 yılı Mayıs-Aralık tarihleri arasında sürekli artış gösteren piyasa değeri 2018 yılı itibariyle düşüşe geçmiştir.

Şekil 1: Bitcoin Piyasa Fiyatı (\$)

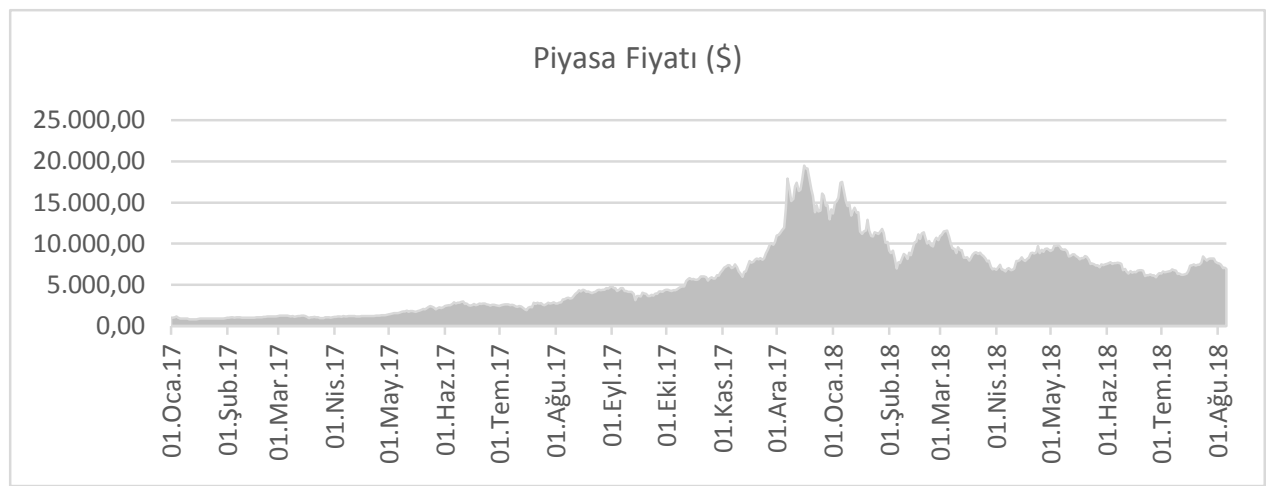

Not: Bitcoin piyasa fiyatına ait veriler 07.08.2018 tarihinde https://coinmarketcap.com/ web adresinden elde edilmiştir. Fiyatlar, gün sonu kapanış fiyatı olarak alınmıştır. 
Şekil 1. 1 Ocak 2017 - 6 Ağustos 2018 tarihleri arasındaki Bitcoin piyasa fiyatını göstermektedir. 2017 yılı Aralık ayı Bitcoin fiyatlarının en yüksek olduğu tarih olarak göze çarpmaktadır. 2018 yılının Mart ayından sonra ise fiyattaki değişim önceki aylara kıyasla daha durağan bir hal almıştır. Ancak yine de önemli düzeyde bir oynaklık söz konusudur.

Bitcoin fiyatlarındaki değişimler yatırımcıların ilgisini çekmiş ve getiri elde etme iştahlarını tetiklemiştir. Bu nedenle, Bitcoin fiyatlarındaki dalgalanmalara paralel şekilde işlem hacminde de hızlı artışlar meydana gelmiştir. Fiyattaki volatiliteden dolayı kısa vadede al-sat ile getiri elde etmeye çalışan yatırımcılar hem işlem hacminin artışına hem de fiyatlardaki oynaklığa katkı sağlamışlardır.

Şekil 2. 1 Ocak 2017 - 6 Ağustos 2018 tarihleri arasındaki Bitcoin işlem hacmini göstermektedir. Bitcoin işlem hacmi grafiği Bitcoin fiyat grafiğine benzemektedir. En fazla işlemin yapıldığı tarih 23.840.899.072\$ ile 5 Ocak 2018 tarihi olmuştur. Ocak 2018 tarihinden sonra fiyatta olduğu gibi işlem hacminde de düşüşler başlamıştır. 6 Ağustos 2018 tarihi itibariyle işlem hacmi değeri 3.925.900.000\$'dır.

Şekil 2: Bitcoin Iş̧lem Hacmi (\$)

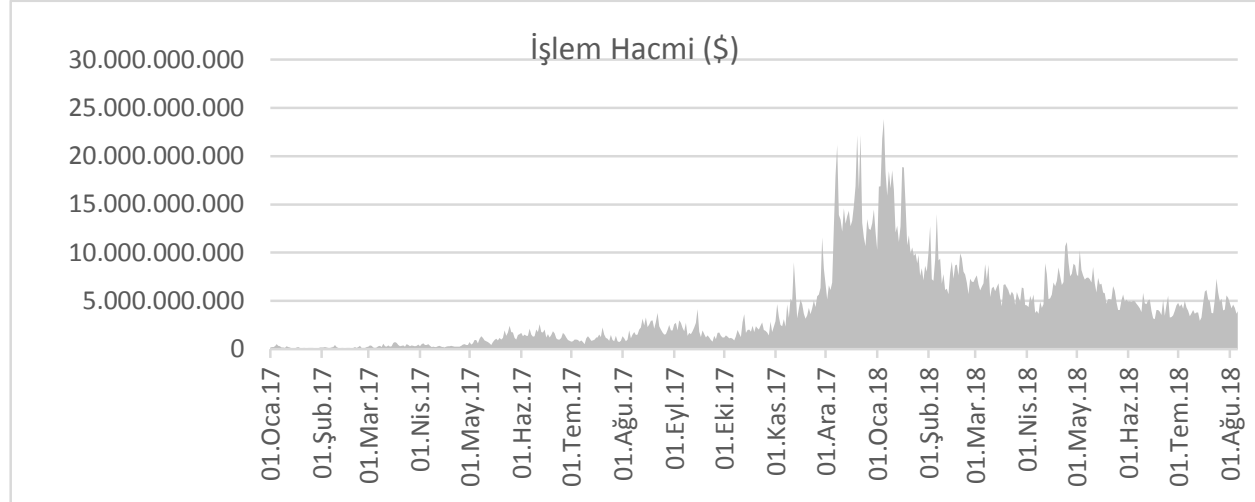

Not: Bitcoin işlem hacmine ait veriler 07.08.2018 tarihinde https://coinmarketcap.com/ web adresinden elde edilmiştir.

Bitcoin'in tarihi çok eskiye dayanmamasına rağmen dünyada birçok kişi tarafından çeşitli amaçlarla kullanılmaktadır. Şekil 2.'de de görüldüğü üzere Bitcoin oldukça yüksek rakamlarda işlem hacmine sahiptir. Bitcoin'in popülerliğinin hızla yükselmesinin arkasında bir takım etmenler yer almaktadır. Bitcoin gibi dijital para birimleri transfer edilebilir varlıklar olup kriptolojik elementler ile güvenlikleri sağlanmaktadır. Dijital paralar herhangi bir devlete bağlı olmayıp organizasyonlar ya da şirketler tarafından üretilmektedir. Ayrıca, bir merkez bankasına da bağlı olmayıp, bir banka hesabında tutulması da gerekmemektedir (Bilir ve Çay, 2016: 24). Bitcoin kullanıcıları Bitcoinlerini özel bir dijital cüzdanda depolamaktadır. Bu cüzdanların herhangi bir kişisel kimliği yoktur. Cüzdanlar sadece bir adres, bir özel şifre ve bir de ortak şifreden oluşmaktadır. Bunun haricinde, kullanıcıyı cüzdana bağlayan başka bir gösterge yoktur. Bu gizlilik derecesi, dijital paraların popülerliğinin arkasında yatan temel nedenlerden biridir (Hencic ve Gourieroux, 2015: 19). 
Bitcoin'in gizliliği popülerliğini doğrudan etkilemiştir. Bunun yanı sıra Bitcoin gibi dijital paraların kullanıcılarına sağladığı birçok avantaj mevcuttur (Brito ve Castillo, 2014; Rogojanu ve Badea, 2016):

- Dijital para alışverişi için fiziksel bir mevcudiyete gereksinim yoktur. Bu nedenle zamandan tasarruf edilir.

- İşlemler istenilen zamanda istenilen yerde yapılabilir.

- Emisyon primi, ulaşım, depolama ve güvenlik maliyetleri yoktur. Ayrıca para ihracı için bürokratik işlemler gerektirmemektedir.

- Bitcoin üretmek için donanım ve güç gerekmektedir. Ayrıca üretilebilecek Bitcoin miktarı 21 milyon ile sınırlandırılmıştır. Bu nedenle altın ile benzer kaliteye sahip denilebilir.

- Bitcoin kullanımı enflasyona neden olmaz. Çünkü limitli para arzı enflasyonla mücadelede önemli bir avantajdır.

- Diğer ödeme yöntemlerine göre çok daha düşük işlem maliyetlerine sahiptir.

- Finansal inovasyonlar için teşvik edici özelliğe sahiptir.

- Yoksullukla mücadele etme potansiyeline sahiptir.

Makro açıdan bakıldığında, Bitcoin finansal kurumların yerini alabilecek bir akım, paranın alternatifi ve yüksek enflasyonlu ekonomiler için bir hedging yöntemidir (Baek ve Elbeck, 2014: 30).

Dijital paraların kolay kullanımı, artan popülaritesi ve hızlı bir şekilde getiri elde etme imkânı dijital para borsalarının doğmasına neden olmuştur. Bitcoin ve diğer dijital paralar, Amerikan Doları ya da diğer para birimleri karşılı̆̆ında sanal piyasalar üzerinden satın alınabilmektedir. Tablo 1. en fazla işlem hacmine sahip Bitcoin borsalarını göstermektedir.

Tablo 1: Bitcoin Borsaları

\begin{tabular}{|c|c|c|c|}
\hline No & Piyasa Adı & İşlem Hacmi (BTC) & Pazar Payı (\%) \\
\hline 1 & Bitfinex & 897.000 & 31,19 \\
\hline 2 & Coinbase & 361.000 & 12,54 \\
\hline 3 & Bitstamp & 306.000 & 10,64 \\
\hline 4 & Kraken & 300.000 & 10,41 \\
\hline 5 & Hitbtc & 278.000 & 9,67 \\
\hline 6 & Bitflyer & 227.000 & 7,89 \\
\hline 7 & Others & 187.000 & 6,49 \\
\hline 8 & Bit-x & 156.000 & 5,44 \\
\hline 9 & İtbit & 86.000 & 2,99 \\
\hline 10 & Gemini & 78.800 & 2,74 \\
\hline
\end{tabular}

Kaynak: Borsalara ait veriler 12.08.2018 tarihinde https://bitcoinity.org/ web adresinden elde edilmiştir.

Tablo 1.'de görüldüğü üzere Bitfinex 897.000 BTC işlem hacmi ile pazar payının \%31,19'una sahiptir. Bitfinex'i \%12,54 pazar payı ile Coinbase ve \%10,64 pay ile Bitstamp izlemektedir.

Dijital paraların kendilerine özgü borsalarının oluşması bu paraların birer yatırım aracı işlevi gördüğünü açıkça ortaya koymaktadır. İşlem hacimleri ise hisse senedi ve tahvil gibi geleneksel 
yatırım araçlarının ve geleneksel borsaların geleceği ile ilgili şüphe uyandırmaktadır. Kısa vadede yüksek getiri elde etmek isteyen yatırımcılar menkul kıymetler yerine dijital paralara yönelebilmektedir. Bu sebeple dijital paraların borsalar üzerindeki etkisi araştırmacılar tarafından incelenmelidir.

Bu doğrultuda, bu çalışmada ile en fazla bilinen ve en fazla pazar payına sahip olan dijital paralardan Bitcoin'in Borsa İstanbul üzerindeki etkisi test edilmiştir. Bu kapsamda, veri olarak Bitcoin piyasa fiyatı ve Borsa İstanbul endeks değerlerinden faydalanılmıştır. Çalışma sonuçlarının portföy çeşitlendirmesi açısından yatırımcılara yol gösterici olacağı düşünülmektedir.

\section{Literatür Taraması}

Bitcoin ortaya çıktığı ilk zamanlarda gerek piyasa değeri gerekse işlem hacminin durağanlığı dolayısıyla sosyal bilimcilerin ilgisini çekmemiştir. Bitcoin ile ilgili yapılan araştırmalar genellikle madencilik başlığı altında teknik bilimciler tarafından incelenmiştir. Bitcoin piyasa değerinin yükselmesi, işlem hacimlerinin artması, yatırım alternatifi olarak değerlendirilmesi araştırmacıların ilgisini çekmiş ve Bitcoin ile ilgili araştırmalarda artış görülmüştür. Bitcoin'in altın, döviz kurları, borsalar vb. ile ilişkileri incelenerek bir yatırım aracı olarak geleneksel yatırım araçlarına alternatif olup olmayacağı sorgulanmıştır.

Literatürde Bitcoin fiyatları ile borsalar arasındaki ilişkiyi inceleyen az sayıda çalışmaya rastlanmıştır. Bitcoin'in bir yatırım aracı ya da spekülatif bir araç olup olmadığını inceleyen Baek ve Elbeck (2015), Temmuz 2010 - Şubat 2014 tarihleri Bitcoin fiyatları ile S\&P500 endeksi verilerini kullanmışlardır. Regresyon analizi sonucunda, Bitcoin fiyatının S\&P500 endeksi üzerinde etkisinin olmadığı gözlemlenmiştir.

Bitcoin fiyatları ile S\&P500 endeksi arasındaki ilişkiyi inceleyen Georgoula vd. (2015), 27 Ekim 2014 - 12 Ocak 2015 tarihi verilerini kullanmışlardır. Analiz sonuçları, Bitcoin fiyatları ile S\&P500 endeksi arasında negatif bir ilişki olduğunu göstermiştir. Araştırmanın sonuçlarına göre S\&P500 endeksi düşüşe geçtiğinde yatırımcılara hisse senetlerini satarak Bitcoin alabilecekleri önerilmiştir.

Bitcoin fiyatlarının borsa endeksleri üzerindeki etkisini inceleyen Dirican ve Canöz (2017), ARDL sınır testi yöntemi ile Bitcoin ve seçilmiş borsa endeksleri arasında eşbütünleşme ilişkisi araştırmışlardır. Veri seti, 24 Mayıs 2013 - 05 Kasım 2017 tarihleri arasındaki Bitcoin fiyatı ve borsa endeks değerlerinden oluşmuştur. Araştırmaya dünyanın önde gelen borsalarından New York Stock Exchange, NASDAQ, London Stock Exchange, Tokyo Stock Exchange, Shangai Stock Exchange, S\&P500 endeksi ve Borsa İstanbul (BiST100) endeksi dahil edilmiştir. Analiz sonucunda, Bitcoin fiyatları ile $A B D$ ve Çin borsa endeksleri arasında eşbütünleşme ilişkisi tespit edilmiştir. Londra, Tokyo ve İstanbul piyasaları ile Bitcoin fiyatları arasında ise herhangi bir ilişkiye rastlanmamıştır.

Bitcoin'in bir riskten korunma aracı olarak kullanılıp kullanılamayacağını test eden Dyhrberg (2015) Financial Times Stock Exchange Endeksi'nde yer alan hisse senetleri, Amerikan doları ve Bitcoin arasındaki ilişkiyi incelemiştir. Çalışmada, veri seti olarak 19 Temmuz 2010 - 22 Mayıs 2015 tarihleri kullanılmıştır. Asimetrik GARCH yöntemi sonuçları Bitcoin'in FTSE endeksinde yer alan hisse senetlerine ve kısa dönemde Amerikan dolarına karşı bir riskten korunma aracı olarak kullanılabileceğini göstermiştir.

Briere vd. (2013), Bitcoin'in portföy çeşitlendirmesi açısından kullanılmasını test etmişlerdir. Bu kapsamda, geleneksel varlıkları (dünya çapındaki hisse senetleri, tahviller, dövizler) ve alternatif yatırımları (emtia, hedge fonlar, gayrimenkul) analizlerine dahil etmişlerdir. Çalışmada veri 
olarak 23 Temmuz 2010 - 27 Aralık 2013 tarihleri arası haftalık veriler kullanılmıştır. Bulgular, Btcoin'in diğer varlıklarla oldukça düşük bir korelasyona sahip olduğunu göstermiştir. Ayrıca, analiz sonuçları Bitcoin yatırımının çeşitlendirmede kullanılmasının önemli faydaları olduğunu ortaya koymuştur.

\section{Ekonometrik Analiz ve Metodoloji}

Çalışmanın ekonometrik analiz kısmında "Bitcoin fiyatları ile Borsa İstanbul BIST 100 endeksi arasında ilişki vardır" hipotezi yapısal kırılmalı zaman serisi analizleri ile test edilmektedir. Çalışmada kullanılacak metodoloji şu şekilde ifade edilebilir; analizlerin başında kullanılacak veri setine ilişkin bilgiler verilerek kurulan hipoteze uygun model kurulmaktadır. Kurulan modelde kullanılan değişkenlerin birim kök içerip içermediğinin analizi için durağanlık testleri yapılmakta ardından ise yapısal kırılmaya izin veren eşbütünleşme ve nedensellik analizleri gerçekleştirilmektedir.

\subsection{Veri Seti ve Model}

Çalışmada 02 Şubat 2012- 06 Mart 2018 dönemlerini kapsayan Bitcoin fiyatları ile BIST 100 endeksi günlük verileri analizlerde kullanılmıştır. Analizlerde kullanılan Bitcoin fiyatları verilerine https://tr.investing.com/ internet sitesi üzerinden 07.03.2018 tarihinde ulaşılmıştır. İlgili kaynakta günlük verilerin başlangıcı ve Bitcoin'in fiyatlanması 02 Şubat 2012 tarihli olduğu için zaman periyodu bu tarih üzerinden sınırlandırılmıştır. Analizlerde kullanılan Bitcoin verilerinin logaritmaları alınarak modele dahil edilmiştir. Logaritmik dönüşümün nedeni, belirli bir tabana göre logaritmaların alınarak değişkenlerin küçültülmesi ve analiz sonuçlarının yorumlanmasında ki kolaylıklardır. Serilerin logaritmalarının alınması verilerde herhangi bir bilgi kaybına neden olmayıp otokorelasyon sorununu da azaltmakta, serilerin normal dağılım göstermesini de arttırmaktadır (Dirican ve Canoz, 2017: 383). Analizlerde bir başka değişken olarak ise Borsa İstanbul BIST 100 endeksi verileri kullanıımıştır. Analizlerde veri seti uyumu açısından hafta sonları borsanın işlem görmemesinden dolayı o günkü fiyatlar son işlem günündeki kapanış endeks fiyatları olarak değerlendirilmiştir. Borsa endeksi verileri ise https://tr.investing.com/ internet sitesi üzerinden elde edilerek logaritmaları alındıktan sonra analizlerde kullanılmıştır. Analizlerde kullanılan veriler ikincil kaynak olarak ifade edilebilirken, TCMB gibi resmi kaynakların veri tabanından alınması güvenilirliğini arttırmaktadır.

Çalışma çerçevesinde bağımlı değişken olarak Borsa İstanbul BIST 100 endeksi ve bağımsız değişken olarak ise Bitcoin fiyatları (BTC) kullanılmıştır. İstanbul BIST'de önemli bir yabancı yatırımcı potansiyeli olduğu düşünüldüğünde, Bitcoin fiyatlarındaki değişimin yabancı yatırımcıları etkileyeceği ve bu nedenle model kurgusunun aşağıdaki şekilde yapıldığı söylenebilir:

$$
B I S T_{t}=\beta_{0}+\beta_{1} B T C_{t}+\varepsilon_{t}
$$

\subsection{Yöntem ve Analiz Sonuçları}

Çalışmanın yöntemi olarak yapısal kırılmaya izin veren zaman serisi analizleri kullanılmaktadır. Analizlerin başlangıcında serilerin durağanlık derecelerinin test edildiği ve literatürde en çok kullanılan ADF ile PP birim kök testleri ile yapısal kırılmaya izin veren durağanlık testlerinden Zivot-Andrews birim kök testi uygulanmıştır. Birim kök testlerinden elde edilecek bulgular neticesinde değişkenler arasında uzun dönemli eşbütünleşme ilişkisinin varlığı için Engle-Granger Eşbütünleşme testi ile yapısal kırılmalı eşbütünleşme testlerinden Gregory-Hansen Testleri kullanılmış ve karşılaştırması gerçekleştirilmiştir. Değişkenler arasındaki nedensellik analizi için ise yeni nesil testlerden Toda-Yamamoto ve Hacker-Hatemi nedensellik testleri kullanılarak elde edilen bulgular yorumlanmıştır. 


\subsubsection{Birim Kök Test Sonuçları}

Ekonometrik çalışmalarda analizlerden önce değişkenlerin birim köklü olup olmadığı durağanlık analizleri ile incelenmelidir. Durağanlık testleri analizlerde sahte regresyon sorunundan kurtulmak için gerçekleştirilir. Granger ve Newbold (1974) çalışmasında, birim kök içeren serilerle yapılan analizlerde sahte regresyon sorunundan dolayı gerçek olmayan sonuçlara ulaşılabileceğini vurgulamıştır. Birim kök sorunu çözülmeksizin yapılan ekonometrik analizlerde değişkenler arasında anlamlı ilişkilerin varlığından bahsetmek yanlış yorumlara ve sonuçlara yol açacaktır (Harris ve Sollis, 2003: 41). Gujarati (1999), ekonometrik testlerde zaman serilerinden faydalanırken varyans ve ortalaması zaman içerisinde değişmeyen iki dönemli kovaryansın yalnızca iki dönem arasındaki uzaklığa bağlı ise değişkenlerin birim köklü olmadığını belirtmektedir. Bitcoin fiyatları ile BIST 100 endeksi arasındaki ilişkinin tespitine ilişkin yapılan analizlerde, serilerin durağanlığı için Genişletilmiş Dickey-Fuller ve Philips-Perron testleri uygulanmıştır.

Tablo 2: ADF ve PP Birim Kök Testi Sonuçları

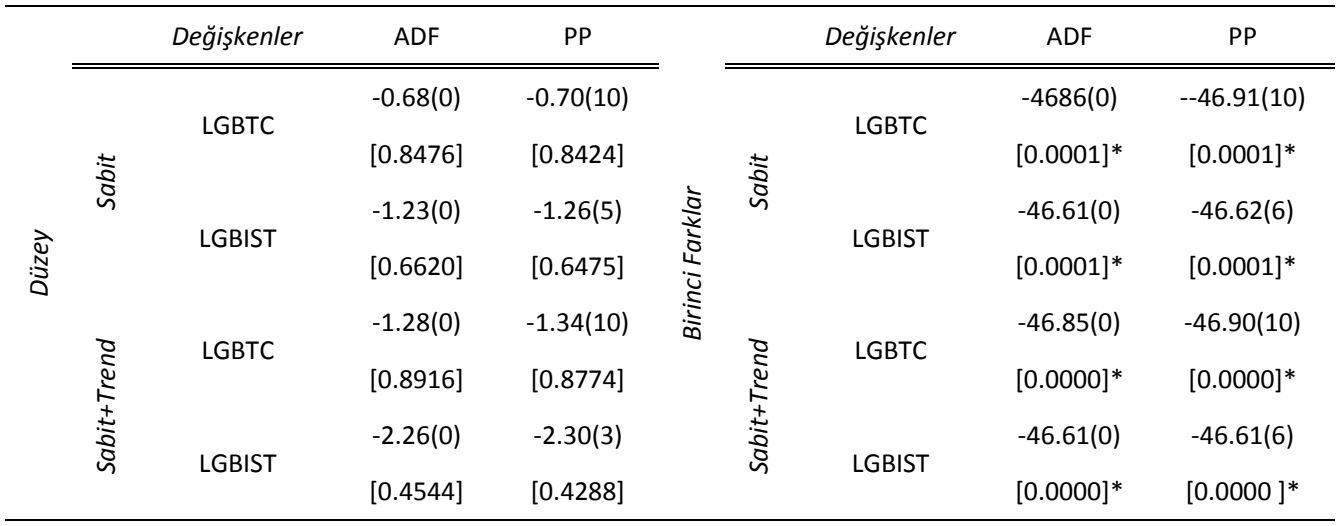

Not: ${ }^{*},{ }^{* *}$ ve ${ }^{* * *}$ değerleri sırasıyla \%1, \%5 ve \%10 seviyelerinde anlamlılı̆ını göstermektedir. Parantez içindeki değerler, uygun gecikme uzunluğunu göstermektedir. Köşeli parantez içindeki değerler olasılık değerlerini göstermektedir.

Tablo 2.'deki sonuçlara göre sabitli ile sabitli ve trendli modelde serilerin ADF ve PP test istatistik değerleri mutlak değerler bakımından karşılaştırıldığında kritik değerlerden küçük olduğu için düzey değerlerinde durağan olmadığı görülmektedir. Durağan olmayan serilerin birinci dereceden farkları alındığında durağanlığına tekrar bakılır. LGBTC ve LGBIST serilerinin birinci dereceden farkları alındığında elde edilen ADF ve PP test istatistiklerinin değerleri \%1 anlamlılık düzeyinde kritik değerden daha büyük olduğu ve sabitli ile sabitli ve trendli modelde durağan hale geldiği anlaşılmaktadır. Her iki değişkenin de I(1) düzeyinde durağan olması, yapılacak eşbütünleşme ve nedensellik analizleri için bir sorun olmayacağı anlamına gelmektedir.

Çalışmada kullanılan zaman serisi analizlerinde seriler farklı deterministik trendler etrafında durağan olabilmektedir. Analizlerde kullanılan değişken ve/veya modellerin sabit teriminde veya eğiminde yapısal kırılmalar oluşabilmektedir. Yapısal kırılmaların nedeni olarak, referans tarihlerde yaşanılan sosyo-ekonomik krizler, doğal afetler, terör olayları, savaşlar gibi gerekçeler sayılabilir. Analizlerde belirtilen döneme bu kadar etkisi olan kırılmaları dikkate almadan yapılan çalışmalar, kullanılan testlerin gücünü ve güvenilirliğini zayıflatmaktadır (Perron, 1989). Bu nedenle çalışmada kırılmanın içsel olarak tespit edildiği Zivot-Andrews birim kök kırılma testi uygulanmıştır. Zivot-Andrews (1992) testlerinde, yapısal kırılmanın kesin olarak tespit edilemediği, içsel olarak belirlendiği süreci incelemektedir. Bu kapsamda yapısal kırılmanın tespiti için aşağıdaki gibi gösterilen üç farklı durağanlık testi geliştirmişlerdir: 


$$
\begin{aligned}
\Delta y_{t} & =\mu^{A}+\theta^{A} D U_{t}(\lambda)+\beta^{A} t+\alpha^{A} y_{t-1} \sum_{j=1}^{k} c_{j}^{A} \Delta y_{t-j}+e_{t} & & \text { (Model A) } \\
\Delta y_{t} & =\mu^{B}+\beta^{B} t+\gamma^{B} D T_{t}^{*}(\lambda)+\alpha^{B} y_{t-1}+\sum_{j=1}^{k} c_{j}^{B} \Delta y_{t-j}+e_{t} & & \text { (Model B) } \\
\Delta y_{t} & =\mu^{C}+\theta^{C} D U_{t}(\lambda)+\beta^{C} t+\gamma^{C} D T_{t}^{*}(\lambda)+\alpha^{C} y_{t-1}+\sum_{j=1}^{k} c_{j}^{C} \Delta y_{t-j}+e_{t} & & \text { (Model C) }
\end{aligned}
$$

Yapılan durağanlık testlerinde Model A-Model B-Model C olmak üzere düzeyde-eğimdehem eğimde hem düzeyde kırılmaları gösteren analizler yapılmaktadır. Analizlerin gerçekleştirilmesinde örneklemdeki her dönem kırılma yılı olarak hesaplanmakta ve oluşturulan kukla değişkenler ile $\alpha$ katsayısının $\mathrm{t}$ istatistik değerleri hesaplanmaktadır. Bu yöntem tüm örneklem üzerinde uygulandığında $t$ istatistiğinin en düşük olduğu yıl, yapısal kırılmanın gerçekleştiği yıl olarak belirlenmektedir. Analizler sonucunda elde edilen istatistik değerler Zivot ve Andrews'in çalışmasındaki kritik değerler tablosu ile karşılaştırılmaktadır. Karar sürecinde ise analizler sonunda hesaplanan $t$ istatistik değerinin mutlak değerinin tablo kritik değerinden küçük olması serinin birim kök içerdiğini gösterir. Tepsi durumunda ise serinin yapısal kırılmayla birlikte durağan olduğu sonucuna ulaşılmaktadır (Korkmaz vd., 2008: 25).

Tablo 3: LGBIST Serisi Zivot-Andrews Birim Kök Test Sonuçları

\begin{tabular}{ccccc}
\hline Model & Kırılma Yılı & t-istatistiği & $1 \%$ & $5 \%$ \\
\hline \hline Model A & 30.01 .2015 & $-9,27^{*}$ & $-5,34$ & $-4,80$ \\
Model B & 29.01 .2013 & $-9,17^{*}$ & $-4,93$ & $-4,42$ \\
Model C & 30.01 .2015 & $-9,27^{*}$ & $-5,57$ & $-5,08$ \\
\hline Not: $* * *$ ve $* * *$ & $\%$ sıras & $\% 10$ anlamlılk düzeyinde katsayıların istatistiksel olarak anlamlı olduğunu ifade
\end{tabular}
etmektedir.

BIST 100 serisi için Zivot-Andrews birim kök testine ait sonuçlara bakıldığında t-istatistiğine göre belirlenen yapısal kırılma dönemlerinde her üç model içinde seriler \%1 anlamlılık seviyesinde düzeyde yapısal kırılmayla birlikte durağan olduğu görülmektedir. BIST 100 serisi kırılma dönemine bakıldığında ise 30.01.2015 ve 29.01.2013dönemlerinde kırılmaların olduğu ve bu tarihlerde ise Ocak 2015 dönemi sonlarında Türkiye'de ki terör olaylarının piyasalar üzerinden ciddi tedirginlikler yarattığı ve kırılmalara neden olabileceği düşünülmektedir. Ocak 2013 dönemi sonlarında ise Merkez Bankası'nın aldığı yüksek orandaki faiz artırımı kararının kırılmaların temel nedeni olduğu söylenebilir.

Tablo 4: LGBTC Serisi Zowot-Andrews Birim Kök Test Sonuçları

\begin{tabular}{ccccc}
\hline Model & Kırılma Yılı & t-istatistiği & $1 \%$ & $5 \%$ \\
\hline \hline Model A & 25.12 .2014 & $-5,58^{*}$ & $-5,34$ & $-4,80$ \\
Model B & 25.04 .2013 & $-4,57^{* *}$ & $-4,93$ & $-4,42$ \\
Model C & 21.10 .2014 & $-6,33^{*}$ & $-5,57$ & $-5,08$ \\
\hline Not: $* * *$ ve $* * *$ sırasıyla \%1, \%5 ve \%10 anlamlılı düzeyinde katsayıların istatistiksel olarak anlamlı olduğunu ifade
\end{tabular}
etmektedir.

Bitcoin serisi için ise Zivot-Andrews birim kök testlerine ait sonuçlarına bakıldığında t-istatistiğine göre belirlenen yapısal kırılma dönemlerinde Model A ve Model C için \%1, Model B için ise \%5 anlamlılık seviyesinde serilerin düzeyde yapısal kırılmayla birlikte durağan olduğu yani birim kök içermediği görülmektedir. Bitcoin serisi kırılma dönemine bakıldığında ise 25.12.2014, 25.04.2013 ve 21.10.2014 dönemlerinde kırılmaların olduğu ve bu tarihlerde ise sosyal, siyasal ve ekonomik anlamda önemli gelişmelerin yaşandığı görülmektedir. Bu olaylara bakıldığında 25.12.2014 terör örgütlerinin mevcut iktidarı yıpratmak için oluşturduğu algı operasyonları, 
25.04.2013 tarihinde Türkiye-İsrail ilişkilerinin bozulması ve 21.10.2014 tarihinde Kobane/Suriye'de yaşanılan olayların piyasalar üzerinde önemli etkiler yarattığı söylenebilir.

\subsubsection{Eşbütünleşme Testi Sonuçları}

Ekonometrik çalışmalarda modele dahil edilen değişkenlerin uzun dönemli ilişkileri eşbütünleşme testleri ile ölçülmektedir. Literatürde, değişkenler arasındaki eşbütünleşme ilişkilerinin tespiti daha çok Engle-Granger ve Johansen-Juselius testleri ile yapılmaktadır. Bu testlerde modelde kullanılan değişkenlerin aynı dereceden durağan olması şartı aranmaktadır. Çalışmada, literatürde en çok tercih edilen Engle-Granger (1987) testi kullanılmış olup devamında ise karşılaştırma yapmak ve yapısal kırılmaları tespit etmek için Gregory-Hansen eşbütünleşme testleri kullanılmıştır.

Kalıntılara dayalı olarak analizlerin gerçekleştirildiği Engler-Granger testinde durağanlığı sağlanan değişkenler arasında öncelikle şu regresyon modeli kurulmaktadır (Yılancı, 2009: 208):

$$
Y_{t}=a_{0}+a_{1} \times 1+u_{t}
$$

Eşbütünleşme testinin ikinci aşamasında EKK yöntemi kullanılarak hata terimi çıkartılır ve elde edilen hata terimleri kalıntılar ile otoregresif model kurgulanarak bu serinin durağanlığı tespit edilir.

$$
\Delta u_{t}=\Delta \rho u_{t-1}+e_{t}
$$

Modelde kullanılan $\rho$ değişkeninin sıfır olması durumunda serinin birim kök içerdiği ve değişkenler arasında uzun dönemli eşbütünleşme ilişkisinin görülmediği söylenebilir. Ayrıca analizler sonunda elde edilen istatistik değerinin ADF kritik değerleri yerine Engle-Granger (1987) makalesinde simülasyonlardan elde edilen kritik değerler ile karşılaştırılmaktadır.

Tablo 5: Engle-Granger Eş-Bütünleşme Testi (LGBTC - LGBIST)

\begin{tabular}{cccc}
\hline ADF Test İstatistiği & \multicolumn{3}{c}{ Engle-Granger Eşbütünleşme Testi Kritik Değerleri } \\
\hline \hline 0,76 & $1 \%$ & $5 \%$ & $10 \%$ \\
& 3,02 & 3,37 & 4,00 \\
\hline
\end{tabular}

Çalışmada modele dahil edilen Bitcoin ile BIST 100 endeksi arasındaki uzun dönemli eşbütünleşme ilişkisinin varlığı için gerçekleştirilen Engle-Granger analizi sonucunda ADF test istatistik değerinin Engle-Granger tablo kritik değerlerinden mutlak değerce küçük olduğu görülmektedir. Bu nedenle iki değişken arasında doğrusal ve doğrusal olmayan uzun dönemli ilişkinin görülmediği sonucuna ulaşılmaktadır.

Engle-Granger eşbütünleşme testinin ardından tek yapısal kırılmayı da dikkate alarak eşbütünleşme ilişkisini test eden Gregory-Hansen eşbütünleşme testi kullanılmıştır. Devamında ise iki test karşılaştırılarak değişkenler arasındaki uzun dönemli ilişki olup olmadığı hakkında politika önermeleri gerçekleştirilmiştir. Amprik çalışmalarda kullanılan birinci nesil eşbütünleşme testlerinde eşbütünleşik vektörün zaman boyutunda değişmediği varsayılmaktadır. Fakat yapısal kırılmaları da dikkate alarak analizleri gerçekleştiren Gregory-Hansen eşbütünleşme testi, vektörün içsel olarak belirlenen kırılma zamanında değişebileceğini belirtmektedir. GregoryHansen alternatif hipoteze karşı, kırılmanın eş-bütünleşmede olabileceğine dayalı alternatif bir hipotez geliştirmişlerdir. Bu testde sabitte-trendli sabitte ve rejim değişiminde kırılmaya izin veren üç model kullanılmaktadır (Gregory ve Hansen, 1996: 555). 
Sabitte kırılma

$$
\mathrm{Y}_{1} \mathrm{t}=\mu_{1}+\mu_{2} \varphi \pi+\alpha^{\mathrm{T}} \mathrm{y}_{2} \mathrm{t}+\mathrm{et}
$$

$\mathrm{t}=1,2,3, \ldots \ldots, \mathrm{n}$

Modelde $\mu_{1}$ kırılmadan önceli sabiti, $\mu_{2}$ ise kırılmadan sonra sabitte meydana gelen değişmeyi göstermektedir. $\mathrm{t}$ ise 0 ile 1 arasında yer alan kırılmanın zamanlamasını gösteren katsayıdır. $\alpha^{\mathrm{T}}$ açıklayıcı değişkenlere ait katsayı vektörünü ifade etmektedir, $\partial \pi$ ise kukla değişkendir. Sabit ve Trendde Kırılma $\quad \mathrm{Y}_{1} \mathrm{t}=\mu_{1}+\mu_{2} \varphi \pi+\beta \mathrm{t}+\alpha^{\mathrm{T}} \mathrm{y}_{2} \mathrm{t}+\mathrm{et} \quad \mathrm{t}=1,2,3, \ldots \ldots ., \mathrm{n}$

Bu modelin temel farkı sabitte kırılmanın yanında trendi de ele almasıdır. Trendi temsil eden değişken $\beta$ t dir ve analizlerde trendde ki kırılma da incelenmektedir.

Rejim Değişimi

$$
\mathrm{Y}_{1} \mathrm{t}=\mu_{1}+\mu_{2} \partial \pi+\alpha_{1}^{\mathrm{T}} \mathrm{y}_{2} \mathrm{t}+\alpha_{2}^{\mathrm{T}} \mathrm{y}_{2} \mathrm{t} \varphi 1 \mathrm{t}+\mathrm{et}
$$$$
t=1,2,3, \ldots \ldots, n
$$

Rejim değişimi modelinde ise $\alpha 1$ rejim değişimi öncesi eşbütünleşme vektörünü, $\alpha 2$ rejim değişimi sonrası eşbütünleşme vektröünde meydana gelen değişmeyi gösterir.

Tablo 6: Gregory ve Hansen Eşbütünleşme Testi Sonuçları

\begin{tabular}{cccccc}
\hline Model & Kırılma Yılı & t-istatistiği & $1 \%$ & $5 \%$ & $10 \%$ \\
\hline \hline C $^{*}$ & 23.06 .2013 & $-3.55(2)$ & -5.13 & -4.61 & -4.34 \\
C/T** & 06.09 .2013 & $-3.65(5)$ & -5.45 & -4.99 & -4.72 \\
C/S*** & 25.04 .2013 & $-3.80(16)$ & -5.47 & -4.95 & -4.68 \\
\hline
\end{tabular}

Not: Parantez içindeki değerler gecikme sayısını ifade etmektedir.

* Sabitte kırılma **Trend de kırılma *** Rejim değişimi

Yapısal kırılma altında modeldeki değişkenlerin aralarında uzun dönemli bir ilişki olup olmadığının tespit edilmesi için uygulanan Gregory-Hansen Eş-bütünleşme testinde minimum ADF sonuçları ile bunlara denk gelen kırılma dönemleri Tablo 6 'da verilmiştir. Tablo incelendiğinde tüm modeller için ADF istatistiği mutlak değer olarak kritik değerlerden küçük olduğu yani Bitcoin fiyatları ile BIST100 endeksi arasında uzun dönemli bir ilişkinin söz konusu olmadığı sonucuna varılmıştır. Kırılmanın yaşandığı 23.06.2013-06.09.2013-25.04.2013 tarihlerinde ise konjontürel veya küresel etkilerin olduğu şeklinde yorumlanabilir.

Çalışmada gerçekleştirilen Engle-Granger Eş-Bütünleşme Testi ile Gregory-Hansen Eş-bütünleşme testleri sonucunda her iki değişken arasında uzun dönemli bir ilişkinin olmadığı sonucuna ulaşılmış ve analiz sonuçları birbirini desteklemiştir.

\subsubsection{Nedensellik Testi Sonuçları}

Nedensellik testlerinde, zaman serisi verilerinin gelecek dönem değerleri ile önceki dönemlere ait geçmiş değerlerden etkilenmesi ile analizler gerçekleştirilmektedi (Isığıçok, 1994: 94). Bitcoin fiyatları ile BIST 100 endeksi arasındaki ilişkinin incelendiği çalışmada, öncelikle ekonometrik analizlerde sıkça kullanılan Toda-Yamamoto (1995) ve devamında ise Hacker ve Hatemi$\mathrm{J}(2006)$ testleriyle nedensellik ilişkisi tespit edilmeye çalışılmıştır.

Toda-Yamamoto testinin Granger nedensellik testinden temel farkı, nedenselliğe bakılan değişkenlerin eşbütünleşik olup olmamasıdır. Granger nedensellik testinde değişkenlerin eşbütünleşik olma şartı bulunmaktadır. Toda-Yamamoto testinde ise eşbütünleşik olma şartı değil önemli olan modelin ve maksimum bütünleşme derecesinin doğru doğru hesaplanması gerekmektedir (Kızılgöl ve Baykal, 2008: 356). Toda ve Yamamoto (1995)'ya göre seriler durağan olmasalar da serilerin düzey değerlerinin yer aldığı VAR modelinin tahmin edilebileceğini ve standart Wald testinin uygulanabileceğini belirtmişlerdir. Bu yöntemde Granger nedensellik testi için, $[\mathrm{k}+(\mathrm{dmax})]$ dereceden VAR model tahmin edilmekte ve katsayılar matrisinin ilk $\mathrm{k}$ tanesine 
Wald testi uygulanmaktadır. Toda ve Yamamoto (1995), ilgili serinin durağan, trend etrafında durağan veya eşbütünleşik olup olmadığı dikkate alınmaksızın, bu testin $k$ serbestlik derecesi ile asimptotik $2 \chi$ dağılımına sahip olduğunu göstermişlerdir. Burada; $k$ tahmin edilen VAR modelinin uygun gecikme uzunluğunu, dmax ise modeldeki değişkenlerin maksimum bütünleşme derecesini ifade etmektedir. Böylece yöntemin ilk aşaması sistemde yer alan değişkenlerin bütünleşme derecesinin tespiti, ikinci aşaması ise sistemin tahminidir. Buna göre yöntemin başarısı, sistemin gecikme uzunluğunun $(k)$ ve serilerin bütünleşme derecelerinin ( $d$ max) doğru tespitine bağlıdır. Toda ve Yamamoto tarafından önerilen bu yöntemin önemli bir özelliği, birim kök ve eşbütünleşme özelliklerinin tespitinde kullanılan potansiyel eğilimli ön testlere gereksinim olmayışıdır. Böylece, ilgili yöntemin kullanımı ile serilerin bütünleşme derecesinin yanlış tespit edilmesi ile ilgili risk minimize edilmektedir.

Çalışmada öncelikle Bitcoin fiyatları ile BIST100 endeksi arasındaki nedensellik ilişkisi TodaYamamoto analizi ile incelenmektedir. Analizden önce bütünleşme derecesinin hesaplanması gerekmektedir. Analize dahil edilen değişkenler için yapılan ADF ve PP birim kök testlerinde tüm değişkenlerin düzeyde birim köklü, 1. Dereceden farkı alındığında ise durağan olduğu görülmüştür. Bu nedenle dmax=1 alınır.

Tablo 7: VAR Modeli Bilgi Kriterlerine Göre LX-LGE Uygun Gecikme Uzunluğu

\begin{tabular}{ccccccc}
\hline Lag & LogL & LR & FPE & AIC & SC & HQ \\
\hline \hline 0 & -2730.274 & NA & 0.041095 & 2.483885 & 2.489064 & 2.485777 \\
1 & 10355.40 & 26135.66 & $2.81 e-07$ & -9.408546 & $-9.393011^{*}$ & $-9.402869^{*}$ \\
2 & 10356.36 & 1.916293 & $2.82 \mathrm{e}-07$ & -9.405783 & -9.379891 & -9.396322 \\
3 & 10358.38 & 4.033743 & $2.82 \mathrm{e}-07$ & -9.403986 & -9.367737 & -9.390740 \\
4 & 10360.63 & 4.479181 & $2.83 \mathrm{e}-07$ & -9.402394 & -9.355788 & -9.385364 \\
5 & 10364.14 & 6.975959 & $2.83 \mathrm{e}-07$ & -9.401944 & -9.344982 & -9.381130 \\
6 & 10370.70 & 13.04262 & $2.82 \mathrm{e}-07$ & -9.404272 & -9.336953 & -9.379673 \\
7 & 10378.97 & 16.42413 & $2.81 \mathrm{e}-07$ & -9.408152 & -9.330476 & -9.379769 \\
8 & 10385.65 & $13.25291^{*}$ & $2.81 \mathrm{e}-07^{*}$ & $-9.410587^{*}$ & -9.322554 & -9.378419 \\
\hline
\end{tabular}

Serbestlik derecesi (k) için ise SC-HQ bilgi kriterlerine göre Tablo 7'de görüldüğü üzere gecikme sayısının 1, AIC bilgi kriterine göre 8 olduğu görülmektedir. Fakat çalışmanın durağanlık analizlerinde Schwarz bilgi kriteri dikkate alınarak testler gerçekleştirildiği için nedensellik testinde gecikme sayısı olarak 1 alınacaktır. Bu nedenle $k+d \max =(1+1)=2$. dereceden VAR modeli çerçevesinde nedensellik yapılmıştır.

Tablo 8: Toda - Yamamoto Nedensellik Analizi Sonuçları

\begin{tabular}{|c|c|c|c|c|}
\hline Temel Hipotezler & $\begin{array}{l}\text { Gecikme Uzun- } \\
\text { luğu k=1, dmax= } \\
1 \\
\end{array}$ & F-ìstatistiği & P-Değeri & Sonuç \\
\hline LGBTC $\nRightarrow$ LGBIST & 2 & 2.6614 & 0.2643 & $\begin{array}{c}\text { Bitcoin fiyatlarından BIST100 endeksine } \\
\text { doğru tek yönlü yönlü Toda ve Yama- } \\
\text { moto nedensellik ilişkisi görülmemekte- } \\
\text { dir. }\end{array}$ \\
\hline LGBIST $\nRightarrow L G B T C$ & 2 & 7.3457 & 0.0254 & $\begin{array}{c}\text { BIST100 endeksinden Bitcoin fiyatlarına } \\
\text { doğru \%5 anlamlılık düzeyinde tek yönlü } \\
\text { Toda ve Yamamoto nedensellik ilişkisi } \\
\text { vardır. }\end{array}$ \\
\hline
\end{tabular}


Toda-Yamamoto nedensellik testi sonuçlarına göre; bütünleşme derecelerinin 2 olduğu ve BIST 100 endeksinden Bitcoin fiyatlarına doğru tek yönlü nedensellik ilişkisinin olduğu sonucuna ulaşılmıştır. Bitcoin fiyatlarından BIST 100 endeksine doğru ise herhangi bir nedensellik ilişkisine rastlanmamıştır.

Hacker ve Hatemi-J (2006) testi, modelde kullanılan değişkenler arasındaki nedensellik ilişkisinin varlığının tespiti için Toda-Yamamoto nedensellik testi kullanılmıştır. Hata terimlerinin normal dağılmama riskine karşı oluşturulan kritik değerler bootstrap yöntemi ile elde edilmiştir. Analizin en temel eksikliği ise pozitif ve negatif şokların çalışmalarda ayırt edilememesidir. Bu bağlamda Hatemi-J (2012) asimetrik nedensellik testi Hacker ve Hatemi-J (2006) Granger nedensellik testinin pozitif ve negatif şoklarının ayrıştırılmış şeklidir (Yılancı, 2013). Hacker ve Hatemi-J Nedensellik testi, $\mathrm{y}_{1 \mathrm{t}}$ ve $\mathrm{y}_{2 \mathrm{t}}$ gibi iki bütünleşik seri arasındaki nedensellik analizinin test edildiğini varsayıldığında şu şekilde özetlenebilir:

$$
\begin{aligned}
& \mathrm{y}_{1 \mathrm{t}}=\mathrm{y}_{1 \mathrm{t}-1}+\varepsilon_{1 \mathrm{t}}=\mathrm{y}_{10}+\sum_{\mathrm{i}=1}^{\mathrm{t}} \varepsilon_{1 \mathrm{i}} \\
& \mathrm{y}_{2 \mathrm{t}}=\mathrm{y}_{2 \mathrm{t}-1}+\varepsilon_{2 \mathrm{t}}=\mathrm{y}_{20}+\sum_{\mathrm{i}=1}^{\mathrm{t}} \varepsilon_{2 \mathrm{i}}
\end{aligned}
$$

\begin{tabular}{|c|c|c|c|c|c|}
\hline \multirow{2}{*}{ Temel Hipotez } & \multirow{2}{*}{ Test İstatistiği } & \multicolumn{3}{|c|}{ Kritik Değerler } & \multirow{2}{*}{ Karar } \\
\hline & & $1 \%$ & $5 \%$ & $10 \%$ & \\
\hline LGBTC $\nRightarrow$ LGBIST & 3.301 & 11.376 & 6.278 & 4.382 & $\mathrm{H}_{0}$ temel hipotez KABUL \\
\hline LGBISTÆLGBTC & 2.091 & 10.251 & 6.551 & 4.921 & $\mathrm{H}_{0}$ temel hipotez KABUL \\
\hline
\end{tabular}

Tablo 9: Hacker ve Hatemi-J Bootsrap Nedensellik Testi

Not: ${ }^{*}, *$ ve ${ }^{* * *}$ sırasıyla $\% 1, \% 5$ ve $\% 10$ anlamlılı düzeyinde katsayıların istatistiksel olarak anlamlı olduğunu ifade etmektedir.

Hacker-Hatemi-J Bootsrap Nedensellik test sonuçlarının yer aldığı Tablo 9'a göre; Bitcoin fiyatları ile BIST100 endeksi arasında MWALD istatistik değerleri bootstrap kritik değerlerinden küçük olmasından dolayı herhangi bir nedensellik ilişkisine rastlanmamış ve "değişkenler arasında nedensellik ilişkisi yoktur" şeklinde kurulan $\mathrm{HO}$ temel hipotezi kabul edilmektedir.

Çalışmada gerçekleştirilen nedensellik analizleri karşılaştıııldığında; sadece Toda-Yamamoto testinde BIST100 endeksinden Bitcoin fiyatlarına doğru tek yönlü nedensellik tespit edilmiş olup Bitcoin fiyatlarından BIST100 endeksine doğru herhangi bir nedensellik ilişkisine rastlanmamıştır.

\section{Sonuç}

Kripto paralar arasında en büyük işlem hacmine sahip olan Bitcoin, her ne kadar son dönemde değer kaybetmeye başlasa da hala farklı bir ödeme aracı veya farklı bir finansal varlık olarak varlığını sürdürmektedir. Küresel ticarette kullanılabilirliği arttıkça da önemli bir yatırım aracı olarak ifade edilebilmektedir. Başlangıç aşamasında, yalnızca madencilik işlemleri ile anılan Bitcoin zamanla takas ve ödeme işlemlerinde de normal bir para olarak kullanılmaya başlanmış ve günümüzde piyasalar tarafından önemli bir yatırım aracı olarak değerlendirilmektedir. 
Yatırım araçlarının değerlenmesini ya da değer kaybetmesini belirleyen temel faktör o yatırım aracının miktarı yani arzı ve o yatırım aracına olan taleptir. Arz boyutu tamamen üretim odaklı olmasına rağmen talep kısmı spekülasyonlardan beslenen bir faktördür. Yatırım araçlarının arzını belirleyen temel faktörler maliyeti ve beklentileri iken talep yapısını belirleyen faktörler değişkenlikler arz etmektedir. 2017 yılı sonu itibariyle maksimum seviyelere yükselen Bitcoin fiyatları 2018 itibariyle beklenmedik kayıplar yaşamıştır. Şüphesiz bu kayıpların ardında spekülatif dalgalanmalar da vardır fakat yatırım araçlarının genel karakteristiği o yatırım aracının ilişkili olduğu alternatifleri ile korelasyonudur.

Çalışmada, uluslararası bir yatırım aracı haline gelen Bitcoin ile bu yatırım aracından etkilendiği düşünülen ve finans piyasalarında önemli yeri olan borsa endeksi arasındaki ilişki incelenmiştir. Bitcoin fiyatları olarak https://tr.investing.com/ internet sitesinden günlük veriler alınırken borsa endeksi olarak ise Borsa İstanbul BIST 100 endeksi günlük verileri kullanılmıştır. Değişkenler arasındaki ilişkinin analizinden önce gerçekleştirilen birim kök testleri sonuçlarına göre seriler aynı mertebeden durağan çıkmıştır. Bu durum seriler arasındaki eşbütünleşme ilişkisinin araştırılabilmesi için gerekli şartı sağlamıştır. Eşbütünleşme testi olarak çalışmada iki test kullanılmıştır. Birincisi literatürde en sık kullanılan Engle-Granger Eşbütünleşme testi iken diğeri yapısal kırılmaya izin veren Gregory-Hansen Eşbütünleşme testidir. Gerçekleştirilen her iki testte de elde edilen sonuçlar birbirini destekler nitelikte olup Bitcoin fiyatları ile BIST 100 endeksi arasında orta ve uzun dönemli bir ilişkiye rastlanmamıştır. Eşbütünleşme testinin ardından ise Toda-Yamamoto nedensellik testi ile Hacker-Hatemi-J Bootsrap nedensellik testleri ayrı ayrı uygulanmıştır. Yapılan nedensellik testleri sonucunda Toda-Yamamoto nedensellik testine göre BIST100 endeksinden Bitcoin fiyatlarına doğru tek yönlü nedensellik tespit edilmiş olup, Hacker-Hatemi-J Bootsrap Nedensellik testlerinde değişkenler arasında herhangi bir nedensellik ilişkisi görülmemiştir.

Çalışmanın literatür başığı altında da belirtildiği üzere ilgili konuda literatürde çok yoğun çalışmalara rastlanmamıştır. Bu kapsamda analizlerden elde edilen sonuçlar literatürdeki var olan çalışmalar ile karşılaştırıldığında; Baek ve Elbeck (2015) ile Baek ve Elbeck (2015) çalışmalarını desteklerken Georgoula vd. (2015) nin çalışmasıyla çelişmektedir.

Analiz sonuçları doğrultusunda, Bitcoin ile Borsa İstanbul arasında orta ve uzun vadede bir ilişkiye rastlanmadığı için yatırımcılar açısından Bitcoin'in portföy çeşitlendirmesinde şu an için risksiz bir yatırım tercihi olduğunu söylemek mümkün değildir. Bu nedenle Bitcoin'in geleneksel yatırım araçlarına alternatif bir ürün olabileceğinden söz edilemez.

Bitcoin yatırımcılarının Borsa İstanbul yatırımları ile Bitcoin yatırımlarını bağımsız değerlendirmeleri gerekmektedir. Gelecekte yapılacak çalışmalarda Bitcoin ile diğer dijital paralar arasında eşbütünleşme testleri yapılarak dijital para portföylerinin oluşturulmasında yön gösterici olunabilir. Uluslararası yatırımcılar açısından ise farklı borsalarla Bitcoin ilişkisinin incelenmesi portföy çeşitlendirmesi hakkında yorum yapmak açısından faydalı olacaktır. 


\section{Eskişehir Osmangazi Üniversitesi IïB Dergisi}

\section{Kaynaklar}

Baek, Chung; Elbeck, Matt (2015), "Bitcoins as an investment or speculative vehicle? A first look", Applied Economics Letters, 22 (1), 30-34.

Barışık, Salih; Demircioğlu, Elmas (2006), “Türkiye'de Döviz Kuru Rejimi, Konvertibilite, İhracat-ïthalat İlişkisi (19802001)", ZKÜ Sosyal BilimlerDergisi, 2 (3), 71-84.

Bilir, Hakan; Çay, Şerif (2016), "Elektronik Para ve Finansal Piyasalar Arasındaki İlişki”, Niğde Üniversitesi ve Idari Bilimler Fakültesi Dergisi, Nisan 2016, 9 (2), 21-31.

Briere,Marie; Oosterlinck,Kim; Szafarz, Ariane (2013). "Virtual currency, tangible return: portfolio diversification with bitcoins": Proceedings of SSRN working paper series, 1-17.

Brito, Jerry; Castillo, Andrea (2013), "Bitcoin A Primer for Policymakers", Mercatus Center, George Mason University, Policy, 29 (4), 3-12.

Dickey, David A.; Fuller Wayne A. (1981), "Likelihood Ratio Statistics For Autoregressive Time Series With A Unit Root", Econometrica, 49(4), 1057-1072.

Dirican, Cüneyt; Canöz, İsmail (2017), "Bitcoin Fiyatları İle Dünyadaki Başlıca Borsa Endeksleri Arasındaki Eşbütünleşme İlişkisi: ARDL Modeli Yaklaşımı İle Analiz", Journal of Economics, Finance and Accounting, 4(4), 377-392.

Dyhrberg, AnneHaubo (2015), “Hedging capabilities of bitcoin. Is it the virtual gold?”, Finance Research Letters, 1-6.

Engle, Robert F.; Granger, Clive W. J. (1987), “Co-Integration and Error Correction: Representation, Estimation, and Testing", Econometrica, 55 (2), 251-276.

Georgoula, Ifigeneia; Pournarakis, Demitrios; Bilanakos, Christos; Sotiropoulos, Daonisios N.; Giaglis, George M. (2015), "Using Time-Series and Sentiment Analysis to Detect the Determinants of Bitcoin Prices", Mediterranean Conference on Information Systems, Samos, Greece, 1-12.

Gregory, Allan W.; Hansen, Bruce E. (1996), "Residual-Based Tests For Cointegration in Models With Regime Shifts", Journal of Econometrics, 70(1), 99-12.

Gujarati, Damodar N. (2003), Temel Ekonometri, (Çev. Ü. Şenesen; G.G. Şenesen), İstanbul: Literatür Yayınları.

Hacker, R. Scott.; Hatemi-J, Abdulnasser (2006), "Tests for Causality between Integrated Variables Using Asymptotic and Bootstrap Distributions: Theory and Application", Applied Economics, 38, 1489:1500.

Harris, Richard; Sollis, Robert (2003), Applied Time Series Modelling and Forecasting. England: John Wiley\&Sonsltd.

Hencic, Andrew; Gourieroux Christian (2015), "Noncausal Autoregressive Model in Application to Bitcoin/USD Exchange Rates", V.-N. Huynh et al. (eds.), Econometrics of Risk, Studies in Computational Intelligence, 583, 17-40.

https://teknochain.com/liste/,(Erişim: 07.08.2018).

https://coinmarketcap.com/all/views/all/, (Erişim: 07.08.2018).

https://bitcoinity.org/, (Erişim: 12.08.2018).

Işığıçok, Erkan (1994), Zaman Serilerinde Nedensellik Çözümlemesi. Bursa: Uludağ Üniversitesi Basımevi.

Johansen, Soren; Juselius, Katarina (1992), "Testing Structural Hypotheses in a Multivariate Cointegration Analysis of the PPP and UIP for U.K.", Journal of Econometrics, 53, 211-244.

Kızılgöl, Özlem; Erbaykal, Erman (2008), “Türkiye'de Turizm Gelirleri İle Ekonomik Büyüme İlişkisi: Bir Nedensellik Analizi”, Süleyman Demirel Üniversitesi Iktisadi Ve Idari Bilimler Fakültesi Dergisi, 13 (2), 351-360.

Koçoğlu, Şahnaz; Çevik; Yasin Erdem; Tanrı̈ven, Cihan (2016), “Bitcoin Piyasalarının Etkinliği, Likiditesi ve Oynaklığı”, işletme Araştırmaları Dergisi, 8 (2), 77-97.

Korkmaz, Turhan; Zaman, Selin; Çevik, Emrah İsmail (2008), “Türkiye'nin Avrupa Birliği ve Yüksek Dış Ticaret Hacmine Sahip Ülke Borsaları İle Entegrasyon İlişkisi”, ZKÜ Sosyal Bilimler Dergisi, 4 (8), 19-44.

Perron, Pierre (1989), "The Great Crash, The Oil Price Shock, And The Unit Root Hypothesis", Econometrica, 57(2), 1361-1401.

Philips, Peter C.B.; Perron, Pierre (1988), "Testing For A Unit Root in Time Series Regression”, Biometrika, 75(2), 335346.

Rogojanu, Angela; Badea, Liana (2014), "The issue of competing currencies. Case study - Bitcoin”, Theoretical and Applied Economics, 21, 1(590), 103-114.

Toda, Hiro Y.; Yamamoto, Taku (1995). "Statistical Inference in Vector Autoregressions With Possibly Integrated Process", Journal Of Econometrics, 66, 225-250. 
Aralık 2018, C. 13, S. 3.

Yılancı, Veli (2009), “Fisher Hipotezinin Türkiye İçin Sınanması: Doğrusal Olmayan Eşbütünleşme Analizi”, Atatürk Üniversitesi Iktisadi Ve Idari Bilimler Dergisi, 23 (4), 205-213.

Yılancı, Veli (2013) Finansal Ekonometri Semineri (1-5Temmuz 2013), 2013 Ders Notları, Sakarya.

Zivot, Eric; Andrews, W. K. Donald (1992), "Further Evidence on the Great Crash, the Oil-Price Shock, and the Unit-Root Hypothesis", Journal of Business\&Economic Statistics, 10 (3), 251-270. 
Eskişehir Osmangazi Üniversitesi IißBF Dergisi 